\title{
China's Low-Carbon Economy Development and Carbon Finance Market Supervision Mechanism
}

\author{
Bowen Yang \\ Law School of Nankai University, Tianjin, China \\ Email: 15222508254@163.com
}

How to cite this paper: Yang, B.W. (2017) China's Low-Carbon Economy Development and Carbon Finance Market Supervision Mechanism. Low Carbon Economy, 8, 97-105.

https://doi.org/10.4236/lce.2017.84008

Received: November 1, 2017

Accepted: December 1, 2017

Published: December 4, 2017

Copyright (c) 2017 by author and Scientific Research Publishing Inc. This work is licensed under the Creative Commons Attribution International License (CC BY 4.0).

http://creativecommons.org/licenses/by/4.0/ (c) (i) Open Access

\begin{abstract}
China planned to set maximum limits for carbon emissions in 2030. This means China will vigorously develop a low-carbon economy to achieve the low-carbon and sustainable transformation. Carbon financial regulation of multilayered embodies in mainly carbon emissions trading and carbon financial derivatives market is not only a secondary market regulation by the national development and reform commission. In reference to a more mature regional carbon emissions trading formation of information exchange, coordination function, inter-regional coordination mechanism to build legislative carbon trading by establishing cross-regional coordination committee. In this article, establishing a multi-level carbon financial regulatory framework, we can effectively regulate the trading of carbon emission rights and the trading of derivatives, thus providing legal protection for China's low carbon economy.
\end{abstract}

\section{Keywords}

Low Carbon Economy, Carbon Financial Regulation, Carbon Emissions Trading Legislation Supervision

\section{Introduction}

China has made great progress in the construction of ecological civilization. Low-carbon and sustainable is an important part of China's economic transformation. Carbon finance is a new financing way combined with $\mathrm{CO}_{2}$ emissions and financing in the view of the climate finance, it not only has the particularity of carbon quotas financing as a new asset, but also has the trading complexity. To ensure the development of the carbon finance business from the perspective of climate financing, we need to formulate, improve and innovate the international carbon finance legal system. The United States, the European Union and 
other developed countries on the legal regulating of the carbon finance have the mature experience. Currently, controlling the emissions of carbon dioxide is the major method to control the atmospheric pollution. According to this condition, the cooperation of the affected states becomes important. Based on the member state in different carbon development stage of realistic background, a composited cross-regional carbon emissions market is satisfied to establish through scientific positioning function of the market, the main task of the stage, the total control, to perfect the market structure, the Legislation Coordination Mechanism and improve supposing measures etc.

\section{Introduction}

\subsection{Introduction of Carbon Finance}

Carbon finance is the means to finance the trading object of carbon emission right. The global climate change has become the concerns the carbon emission trading has developed remarkably in China while global trading grows rapidly. Carbon trading will provide its market mechanism. Building regional carbon trading and the cross-regional carbon trading mechanism emissions. Establishing cross-regional carbon trading mechanism is an effective way and a priority to reduce emission level and cope with climate change and master initiative rights on climate change negotiations [1]. It is suggested that we should follow the way of regional experiments and implementation in China. Based on the practice and experience of RGGI, it's put a forward the pathway of cross-regional carbon emission system and purpose policy suggestion. Carbon finance refers to serve the aims to reduce greenhouse gas emissions of various financial system arrangement and financial trading activities, including carbon emissions and its derivatives trading and investment, low carbon project investment and financing, and other related financial intermediary activities. In fact, carbon emission is regarded as a commodity which can be traded in stock, futures and so on. The rise of "carbon finance" is the result of the change of the international climate policy, accurately, involving two significant international conventions, the United Nations framework convention on climate change, the Kyoto protocol and the Paris agreement. With the strengthening of the property of carbon dioxide emission rights and the increasing maturity of the market, more and more financial institutions have taken a fancy to the commercial opportunities of carbon market. In addition to the provisions of paper, metal, heat, oil refining and energy-intensive five industries, 12,000 companies actively involved and investment Banks, hedge funds, private equity funds and securities companies and other financial institutions also plays a different role in the carbon market. Initially, financial institutions were only intermediaries for corporate carbon trading, earning slightly more than 1 per cent. There are also funds that look to the potential for appreciation of carbon dioxide emissions and invest directly. The EU carbon quotas from December 2004 less than 9 euros rose to their highest 32 euros in April 2006, although the middle also experienced larger shocks, but also to the $250 \%$ increase in 16 months to fund 
tasted the sweets. The involvement of financial institutions has increased the capacity of the carbon market, increased liquidity and the market has become more transparent. A mature market, in turn, attracts more companies, financial institutions and even private investors, and the form is more diverse. The growing wholesale market for carbon dioxide emissions has led to a surge in interest from private investors in retail sales of carbon dioxide. In October 2006, Barclays capital pioneered the introduction of a standardized over-the-counter emission reduction contract.

\subsection{Methods}

Collecting articles, getting lately researches and studies, studying the present articles, the author has systematical frame of present carbon trading legal system, trading schedule, and typical cases of carbon trading legal system in and out of China which is good to do further researches in future.

This paper uses the comparative analysis, investigation, empirical analysis, literature study, empirical analysis and other research methods. Comparative jurisprudence refers to the knowledge of comparative law and the method of comparative study of jurisprudence. Comparative jurisprudence is a comparative study of the laws of different countries, including the method of comparative study between domestic law and foreign law or between different foreign laws. The empirical research method is based on the research object of observation, experiment and survey, to obtain the objective material, from individual to general, summing up the nature and law of development of things of a kind of research method. The general process of the literature method consists of five basic links, namely: project or hypothesis, research design, literature collection, literature review and literature review. The project or hypothesis of the literature method refers to the idea of analyzing or reclassifying the literature based on existing theories, facts and needs. Study design should first establish the research target, the target refers to using the definition of operational methods, design of the content of the topic or assumed into concrete, can operate, can be repeated literature research activity, it can solve the problem of special and has a certain significance. Interdisciplinary based on the international carbon finance related theory, analyzed the Kyoto era climate finance legal system, the Paris agreement ear climate finance legal system, then analyzed the legal shortcoming and the advice of perfection and innovation. It also analyzed the Trump U.S. government would withdraw from the Paris agreement and stop the United States support for the United Nations climate change capital projects. Furthermore, by comparing EU and USA's carbon trading legal system, set forth useful suggestions to China's setting-up of carbon trading legal system. It will cause national climate finance impact [2].

Therefore, improvement and innovation of the international carbon finance legal system will strengthen the international climate financing cooperation between countries. The legal system will protect the international carbon finance 
market orderly development. At present, China has more financing methods in the international climate financing, at the same time, China also has a lot of international carbon finance projects, CDM projects, etc. However, China lack of the legal regulating of the institution, the products and services. Therefore, establish the Chinese carbon financial legal system is very important. There must be much great significance to build the carbon market.

\section{Feasibility Analysis of Carbon Finance Legislation Supervision}

As a kind of stimulating means of carbon emission reduction economy totally free carbon emission trade can induce the financial risk due to the inherent flaws of the market, such as unfairness of social distribution of carbon emission permit, and imperfect competition of carbon emission permit trade. The government needs to cultivate the external conditions the market will replace the government to play a fundamental regulatory role when the market becomes mature gradually. When the market works improperly, the government can correct it. China's carbon emission permit trading has the necessity and feasibility of government supervision. The regulation of carbon market should first focus on the basic system construction of the whole carbon market [3]. These basic systems involve the trading targets, trading modes, trading subjects, regulators and executing agencies of the carbon market. Highly concentrated market participation is more important to rules and regulations, safeguard the fairness and justice of trading, financial security, the public's full participation, market transparency, the legitimate rights and interests of investors is inviolable, and market the punishment of illegal ACTS, etc. In the regulation of carbon market, the self-discipline of industry groups is the most basic means of carbon market regulation. Regulators should regularly audit and evaluate the supervision of exchanges and other relevant self-regulatory bodies to ensure their compliance [4].

At present, China's carbon emissions trading is mainly based on project transactions, and commercial Banks are more involved in the financing of the CDM. And China occupies a considerable proportion in the market of seller of the CDM market. The number of CDM projects makes the carbon finance based on CDM have a lot of room for development in China. In general, China's carbon trading market has not been formed, and some commercial Banks remain on the sidelines as a result of the unsound laws and regulations related to carbon finance. For this situation, the bank of communications, chief economist expressed: due to lack of experience, the commercial Banks of carbon trading dynamic master is not enough in-depth, bear the risk of big development and trading. In addition, due to China's commercial Banks to engage in carbon finance business is relatively single, mainly concentrated in the downstream and relatively low value-added links, for project consultation, less involved in areas such as a secondary market. Firstly, the sub-industry supervision model has not been able to adapt to the current development of the operation of the 
tear-industry industry, and finally ensure the rational allocation of environmental resources in the market. The two real requirements, cannot discover risk and effective control risk in time. The second is to study the target conflict between the supervision of the listed financial institutions and the regulation of the listed financial institutions while affirming the dominant position of the government in the carbon financial market. Three is a developing government how to give financial holding public financial supporting policies, such as time (2011) also think that the appearance of the department of supervised respectively exposed many malpractices, the regulation of carbon content development financial comprehensive suite of carbon finance development policy should be perfected. The third is close, functional repetition: status equality, the position of each individual; Information cannot be Shared and difficult to discuss in the Kyoto protocol. At home, it is also difficult to find communication and coordination of carbon financial risk, economies of scale; regulatory vacuum and other issues. Fourth, research on the supervision of the eyes. It is not conducive to the diversified foreign financial system to regulate the diversification of the business.

\section{Foreign Experience in Low-Carbon Financial Regulation}

Before the linkage of carbon market, the compatible problems of the design principle of carbon commodity, carbon offsets credit, the monitoring target of carbon emission, contain measure of carbon price become the main obstacle to the linkage of carbon market. After the linkage of the carbon market, the participant of the linkage will benefit from the scale In order to fully get the benefit of linkage of carbon market and avoid risk, the decision makers need take into account the target of linkage, to strengthen the risk monitoring and international policy coordination [5]. Regulators market participants can be comprehensive market position information collection as part of the market supervision system, the implementation of comprehensive big traders reporting system, through the access to market information evaluation of big dealer's market position and market behavior, prevention and control. Regulators tend to adopt market position limits, limit the number of single institutions holding carbon quotas and credit or within a certain time limit its volume, monitor the huge trading, market manipulation to prevent a single organization and abuse of dominant market position.

\subsection{EU Carbon Emissions Quota Finance}

Considering most of the quota allocation principles and methods in the EU's Member States have various sectors. Study the grandfather method distribution principles allocation and standards law principles. Learning the free allocation of quota distribution and full auction allocation, proposed the advantages and disadvantages of this two-allocation method. Free allocation will make more and more enterprises into the system, complete auction is the most efficient way, but it faces many difficulties; mixed distribution way is a way of transition, can bet- 
ter adapt to the carbon trading system by the enterprises, in order to realize efficient distribution of auction to lay a solid foundation [6].

\subsection{The Supervision of EU's Carbon Finance Trading Mechanism}

The carbon trade market was established according to the regulations, in this market, people do transactions by the use and circulation of carbon emission quota. Unlike physical goods, the quota of carbon emissions is not tangible, which leads to the difficulty of the supervision of this market, and from the very beginning, this man-made market has many defects which become increasingly evident in the process of its development. With constant occurrence of carbon trade scandal of carbon trade supervision system bases on the development of their national carbon markets. The government of USA, although hasn't formed the countrywide system of compulsory carbon trading legal system, has very effective voluntary carbon trading legal system, especially the schedule-design of Chicago Exchange which gave useful suggestions to other countries' carbon trading legal system.

EU's legislative response to climate changes and agrees with the role of local governments in their cooperation of ecological management. The paper also argues that relevant legislation should be positioned as a "promotion oriented legislation" with regional legislation as early attempts breaking through the concept of cooperation by expanding the dimension of cooperation, and using incentive measures and legal liability appropriately.

\section{China Low-Carbon Finance Legislation System Construction}

\subsection{Construct “Measurable, Reportable, Verifiable” Legal System}

The MRV management mechanism generally includes three parts: measurement, reporting and verification. Including direct monitoring of transaction data is the primary means of identifying market manipulation and violations. Violations mainly include money laundering, internal transactions, customer fraud, fictitious transactions, price-fixing, and illegal pre-transactions. The regulator should combine the transaction data of the exchanges, regulate the internal trading activity, and safeguard the effective operation of the futures option market. Table 1 is the performance of carbon trading under the existing supervision system in China. The core of non-compliance mechanism of UNFCCC is the supervision system. The existing Kyoto mechanism supervision system includes reporting system, registration system and compliance mechanism. The trend of the post 2012 international climate. The new international rules of MRV system is going to be modified and reconstructed under the framework of UNFCCC and Kyoto Protocol. The international standard is to be further unified and clarified. The MRV rules of local pilot sites of carbon emissions trading have showed different content and features. The unity of MRV system and legal regulatory framework needs to be established in the national carbon emissions trading system. 
Table 1. A summary of the performance of China's carbon emissions trading pilot 2013-2016.

\begin{tabular}{ccccc}
\hline CITY/YEAR & 2013 & 2014 & 2015 & 2016 \\
\hline Shenzhen & $99.4 \%(631 / 635)$ & $99.7 \%(634 / 636)$ & $99.8 \%(635 / 636)$ & $99 \%(803 / 811)$ \\
Beijing & $97.1 \%(403 / 415)$ & $100 \%(543 / 543)$ & $100 \%(543 / 543)$ & $100 \%(945 / 945)$ \\
Shanghai & $100 \%(191 / 191)$ & $100 \%(190 / 190)$ & $100 \%(191 / 191)$ & $100 \%(310 / 310)$ \\
Tianjin & $96.5 \%(110-114)$ & $99.1 \%(111 / 112)$ & $100 \%(109 / 109)$ & $100 \%(109 / 109)$ \\
Guangdong & $98.9 \%(182 / 184)$ & $98.9 \%(182 / 184)$ & $100 \%(186 / 186)$ & $100 \%(244 / 244)$ \\
Hubei & $\begin{array}{c}\text { Temporarily not } \\
\text { released }\end{array}$ & $100 \%(138 / 138)$ & $100 \%(168 / 168)$ & $\begin{array}{c}\text { Temporarily not } \\
\text { released }\end{array}$ \\
& $\begin{array}{c}\text { Temporarily not } \\
\text { released }\end{array}$ & $\begin{array}{c}\text { Temporarily not } \\
\text { released }\end{array}$ & $\begin{array}{c}\text { Temporarily not } \\
\text { released }\end{array}$ & $98.6 \%(273 / 277)$ \\
\hline
\end{tabular}

Data source: China carbon emissions trading network: http://www.tanpaifang.com.

\subsection{Low-Carbon Finance under Government Supervision}

As a kind of stimulating means of carbon emission reduction economy, carbon emission permit trade can not only mitigate the climate change, but also ensure energy security. However, totally free carbon emission permit trade can induce the financial risk due to the inherent flaws of the market, such as unfairness of social distribution of carbon emission permit, and imperfect competition of carbon emission permit trade. The government needs to cultivate the external conditions for the good running of the market as the development of the carbon emission permit trade market is not mature. The market will replace the government to play a fundamental regulatory role when the market becomes mature gradually. When the market works improperly, the government can correct it [7]. By the analysis of the basic principle of the carbon emission permit trading, China's carbon emission permit trading has the necessity and feasibility of government supervision.

\section{Conclusions}

Carbon financial regulation of multilayered embodies in mainly carbon emissions trading and carbon financial derivatives market is not only a secondary market regulation by the national development and reform commission, but also by the securities and futures commission and other regulatory agencies. The regulatory regime overlaps and is chaotic, and lacks the regulatory principles and tools for carbon finance and its derivatives. Based on the reference of the multi-level carbon financial regulatory framework of developed countries outside the region, the principle of independent prudence, the principle of dynamic capital supervision, the principle of risk early warning and the regulation of carbon financial self-regulation are put forward. Regulatory system, by setting up carbon financial supervisory commission, under the financial stability of the development committee as a whole, the coordination of the securities and futures commission, the China banking regulatory commission, insurance regula- 
tory commission for the regulation of carbon finance and its derivatives. Reconstruct China's carbon financial regulation system, formulate the principles and norms of China's carbon finance, and select the appropriate regulatory tools. Whether it is the innovation of regulatory tools or the innovation of the regulatory system, it is aimed at ensuring the demand and effect of financial regulation. By setting up a professional, independent of the financial supervisory commission, coordinate with other regulators, from the traditional functional regulatory and institutional regulation mode gradually transformed into a comprehensive regulatory mode, under the financial stability of the development committee under the state council as a whole, both the present situation and the separate operation in our country, put forward the carbon financial supervision mode, guarantee the carbon efficiency of financial regulation, this is the low carbon economy development in our country, promoting the green, the inevitable choice of the financial system. The government should be establishing a multi-level carbon financial regulatory framework, it can effectively regulate the trading of carbon emission rights and the trading of derivatives, thus providing legal protection for China's low carbon economy.

However, in the context of low carbon economy, carbon finance must have broad development prospects through strong market players, institutional arrangements and innovative tools.

The limitations of this study are based on the main problems of the development of carbon finance market, in the research of macro system and policy: first, the uncertain future international climate negotiations. Second, really can achieve a few in the exchanges, in this context will make a lot of trading under the environment of lack of monitoring, combined with the lack of perfect domestic carbon emissions trading Formation mechanism, which makes carbon prices below the international price level for a long time, there are deficiencies of the research on these.

\section{References}

[1] Xia, B. and Li, Y. (2012) Analysis on the Impact of Tax Policy over China's New Energy Industry Development. Physics Procedia, 25, 1277-1284.

https://doi.org/10.1016/j.phpro.2012.03.233

[2] Han, L. and Kung, J.K. (2015) Fiscal Incentives and Policy Choices of Local Governments: Evidence from China. Journal of Development Economics, 116, 89-104. https://doi.org/10.1016/j.jdeveco.2015.04.003

[3] Shao, Y.Y., Redrigo, H. and Liu, P. (2015) Government Intervention and Corporate Policies: Evidence from China. Journal of Business Research, 68, 1205-1215. https://doi.org/10.1016/j.jbusres.2014.11.015

[4] Gao, P. (2015) Government in the Catching-Up of Technology Innovation: Case of Administrative Intervention in China. Technological Forecasting \& Social Change, 96, 4-14. https://doi.org/10.1016/j.techfore.2015.01.014

[5] Guan, J.C. and Yam, R.C.M. (2015) Effects of Government Financial Incentives on Firms' Innovation Performance in China: Evidences from Beijing in the 1990s. Research Policy, 44, 273-282. https://doi.org/10.1016/j.respol.2014.09.001 
[6] Li, X.N. and Li, Y.F. (2011) Diving Forces on China's Circular Economy: Form Government's Perspectives. Energy Procedia, 5, 297-301.

https://doi.org/10.1016/j.egypro.2011.03.051

[7] Stokes, L.C. (2013) The Politics of Renewable Energy Policies: The Case of Feed-In Tariffs in Ontario, Canada. Energy Policy, 56, 490-500.

https://doi.org/10.1016/j.enpol.2013.01.009 